the cycle threshold mean of the in-house assay and those of both commercial kits.

Conclusion Both commercial kits allowed prompt and specific results, validated by the use of an internal amplification control.

\section{P2.049 NAATS FOR GONORRHOEA DIAGNOSIS IN WOMEN: EXPERIENCE OF A TERTIARY CARE HOSPITAL IN NORTH INDIA}

doi:10.1136/sextrans-2013-051184.0314

${ }^{1}$ S Sood, 'R Verma, 'S Mir, 'M Agarwal, ${ }^{1} \mathrm{~N}$ Singh, ${ }^{2} \mathrm{H}$ K Kar, ${ }^{1} \mathrm{~V}$ K Sharma. 'All India Institute of Medical Sciences, New Delhi, India; ${ }^{2} \mathrm{Dr}$. R M L Hospital, New Delhi, India

Background Gonorrhoea is among the most frequent of the estimated STIs and health implications related to morbidity and mortality especially in women and children are significant. The use of nucleic acid amplification tests (NAATS) has been shown to provide enhanced diagnosis of gonorrhoea in female patients \& are considered the standard for diagnostic purposes currently. However, it is recommended that an on-going assessment of the test assays should be performed to check for any probable sequence variation occurring in the targeted region. In the present study, an in-house PCR targeting opa-gene of Neisseria gonorrhoeae was used in conjunction with $16 \mathrm{~S}$ ribosomal PCR to determine the prevalence of gonorrhoea in female patients attending the tertiary care hospitals

Methods Endocervical samples collected from 250 female patients attending the Dermatology and Gynaecology OPD of AIIMS and STD clinic of Dr. R.M.L. Hospital, New Delhi, India were tested using opa and $16 \mathrm{~S}$ ribosomal assay. Additionally, they were processed by conventional methods. True positives were defined as ones which were positive by culture and/or positive by both $16 \mathrm{~S}$ ribosomal gene and opa-gene based PCR.

Results Of the 250 female patients, only 1 was positive by conventional methods, i.e., microscopy and culture. Based on PCR results, opa-gene based PCR was positive in 17 patients who were also positive by $16 \mathrm{~S}$ ribosomal PCR. However, $16 \mathrm{~S}$ ribosomal gene based PCR picked up 8 extra positives. Overall, 17 patients were found to be true positives.

Conclusion The clinical sensitivity of conventional methods for the detection of $N$. gonorrhoeae in female patients is low. The gonococcal detection rates increased significantly when molecular method was used giving a prevalence rate of $6.8 \%$. However, it is pertinent to mention that the widespread use of NAATs might result in lack of isolates and ignorance of possible emergence of resistant organisms.

\section{P2.050 DEVELOPMENT OF MOLECULAR BEACON BASED DIAGNOSTIC ASSAY FOR DETECTION OF NEISSERIA GONORRHOEAE AND CHLAMYDIA TRACHOMATIS}

doi:10.1136/sextrans-2013-051184.0315

D Sachdev, A L Patel, I Kumari, D Saluja. Dr. B.R. Ambedkar Center for Biomedical Research, University Of Delhi., Delhi, India

Background Due to absence of cost effective and rapid diagnostic test syndromic management of Neisseria and Chlamydia was recommended in developing countries. Being nonspecific such a strategy has resulted in over treatment leading to increased drug resistance. It also misses out on asymptomatic patients resulting in increase in disease burden. The study describes the development and evaluation of a low cost duplex PCR method (dPCR) for codetection of Neisseria and Chlamydia. Using molecular beacons we further provide a method for quantitative and easy detection of the two pathogens.

Methods Endocervical swabs were collected from patients visiting gynaecology department of various hospitals in Delhi. We standardised and evaluated in-house uniplex PCR (uPCR) for diagnosis of Neisseria against Roche Amplicor Micro Well Plate CT/NG kit. Method was modified to co-detect N. gonorrhoeae and C. trachomatis in single test. Further we developed visual assay for detection of Chlamydia and Neisseria using molecular beacon probe.

Results Clinical samples $(n=412)$ were used to validate in-house uPCR assay for Neisseria. The PPV and NPV were found to be $86.77 \%$ and $97.2 \%$. We further modified our uPCR to dPCR for simultaneous detection of Neisseria and Chlamydia. The overall infection rate was found to be $27.8 \%$ and $26.3 \%$ for Neisseria and Chlamydia respectively while $11.3 \%$ of patients were co-infected. The in-house dPCR was found to be $85.7 \%$ sensitive and $97 \%$ specific. To further enhance the sensitivity and specificity of our test, molecular beacon were designed against the amplicons. Use of molecular beacons also reduced the detection time as amplicons could be directly visualised under dark reader.

Conclusions The in-house APCR assay is rapid and as sensitive as commercially available tests. Use of molecular beacons provides a highly specific and easy to use detection method, making it a better option for routine diagnosis of genital infection in developing countries.

\section{P2.051 A COST-EFFECTIVE AND SIMPLE ALTERNATIVE TECHNIQUE FOR RESUSCITATION OF FREEZE-DRIED CULTURES OF NEISSERIA GONORRHOEAE}

doi:10.1136/sextrans-2013-051184.0316

M Bala, V Singh, M Kakran, V Ramesh. VMMC \& Safdarjung Hospital, New Delhi, India

Background Freeze drying (lyophilization) of bacteria is a very well established method for the archiving and long-term storage. The recommended medium for resuscitation of freeze-dried cultures of Neisseria gonorrhoeae is $1 \mathrm{ml}$ of a nutrient blood broth or a rich peptone broth supplemented with $10 \%$ blood or nutrient broth. Sheep blood or horse blood is not easily available in most of the labs. and human blood is not recommended. Normal saline $(0.9 \% \mathrm{~W} / \mathrm{V}$ Sodium chloride) is mostly available in all the labs. This study compared the nutrient blood broth and normal saline for resuscitation of freeze-dried cultures of reference and clinical strains of $\mathrm{N}$. gonorrhoeae and evaluated their performance characteristics for the growth of $\mathrm{N}$. gonorrhoeae strains.

Methods A prospective study was undertaken between January 2011 and December 2012. Ninety three N. gonorrhoeae lyophilized strains including 83 clinical isolates, ATCC 49226 and nine WHO reference strains were tested using both the methods. Reconstituted material from both the techniques was subcultured on to chocolate agar and was incubated for $24-48 \mathrm{hrs}$ at $36^{\circ} \mathrm{C}$ in a moist atmosphere containing 5 to $10 \%$ carbon dioxide. The results were recorded in terms of viable gonococci, colony morphology and colony size.

Results N. gonorrhoeae was successfully isolated from 89 (95.7\%) lyophilized strains by both the techniques used for revival. In other 4 cases, it was difficult to state with absolute certainty that the gonococci were nonviable or that unsatisfactory lyophilization practises were responsible for these results as the quality of the lyophilsed strains also determined the growth on revival.

Conclusion Preliminary data suggest that nutrient blood broth and normal saline were equal in performance for revival of lyophilized strains and normal saline could be recommended as convenient and inexpensive alternative for universal use.

P2.052 ANALYTICAL EVALUATION OF THE SPECIFICITY AND
NEISSERIA GONORRHOEAE DETECTION OF THE NOVEL
GENEPROOF N. GONORRHOEAE DUAL-TARGET PCR ASSAY

doi:10.1136/sextrans-2013-051184.0317

B Hellmark, D Golparian, M Unemo. WHO Collaborating Centre for Gonorrhoea and other STIs, Department of Laboratory Medicine, Microbiol, Örebro, Sweden 